\title{
Methodological Guide for Incorporating Academic Competencies to the Curriculum of an Academic Program Through Régnier's Abacus Technique
}

\author{
Raúl J. Martelo ${ }^{\# 1}$, Diofanor Acevedo ${ }^{* 2}$, Piedad M. Martelo ${ }^{\$ 3}$ \\ \# Faculty of Engineering, Research Group in Communications and Informatics Technologies GIMATICA- \\ INGESINFO. University of Cartagena. \\ * Faculty of Economics Science, Research Group NUSCA. University of Cartagena \\ ${ }^{\$}$ Faculty of Dentistry. University of Cartagena. \\ ${ }^{1}$ rmartelog1@unicartagena.edu.co, ${ }^{2}$ diofanor3000@gmail.com, ${ }^{3}$ pmonteroc@unicartagena.edu.co.
}

\begin{abstract}
The aim of this research was to propose a novel methodological guide for incorporating of academic competences to the curriculum of the higher education institutions through Régnier's Abacus technique. SoftProsp Software was employed to use the technique. It was taken as a particular case, the curriculum of Systems Engineering of the University of Cartagena and the domain of Software Defined Networking (SDN) as competence. The obtained results allowed to analyse the curriculum of the Systems Engineering program of the University of Cartagena and determinate the competencies that must be integrated to complement the professional profile of the graduate. Application of the technique that allows to link up new competences to curriculum that are needed by professionals of university academic programs.
\end{abstract}

Keyword - Curriculum, Software Defined Networking, competences.

\section{INTRODUCTION}

Higher education institutions (HEIs) are obliged to impart knowledge through academic programs to train professionals capable of solving society's needs effectively. For this reason, it is necessary formulated and provide a curriculum that strengthens the academic competencies of students, which describe the fundamental knowledge and skills that are required to successfully complete a college program [1]. Besides, it must be in accordance with market criteria in order to cover the demand that exists and innovate with products or services that facilitate are performed both labor and personally.

In the HEIs exist academic programs to comprise areas such as alimentation, health, construction and technology, with the purpose of complement and strengthen the development of society. From these, a curriculum is created to contain competences that cover related knowledge, to provide the pertinent approach to students. Thus, for the curriculum design, mainly a competences descriptor is used to set the ratio between the program and desired profile, then it is described the learning results and criteria for evaluation; each one of them has cognitive, procedural and attitudinal contents that the student must manipulate to reach the proposed learning [2]. Moreover, it must be held into account the innovations in trends and technologies on the market, these produce the need to incorporate elements to the functioning of the educational system [3].

The competences in the curriculum are included in order to allow for the student to address present situations and provide an adequate solution. Studies have been carried out where describing competencies for engineering students enrolled in undergraduate programs, through the methodological approach of Romanian higher education which focuses on quality assurance and prioritizes learning outcomes and the formulation of the objectives of the course in terms of knowledge, skills and know-how [4].

On the other hand, it has been proposed methodologies to compare the professional competencies of employers with those acquired during the educative process, in order to harmonize and adapt the curriculum of universities to the specific needs of organizations [5]. In the definition of the suitable competences for the professional, techniques are used to support this process, e. g., it has been developed news competencies for the library professional people and information/science studies, through the review of documents from Special Libraries Association (SLA), American Library Association (ALA) and Association of Southeastern Research Libraries (ASERL), regarding the subject under study [6]. The application of this tool allows an analysis for the estimation of trends that affect the development of HEIs, so those possible scenarios are constructed in order to make correct decisions and to accelerate the processes of strategic planning through techniques such as MICMAC, Consensus, morphological analysis and Regnier's Abacus technique [7]. This last one is a technique 
which allows to consult the opinion of experts based on a voting for the colour scale (green, light green, yellow, light red, red, white and black), for easing the result interpretation [8].

The technique has been applied in studies to establish the factors that have the greatest impact on the automobile theft system, among the 34 that represented the system [9]. Also, it has been designed a methodological guide that establishes steps to define the professional profile in academic programs through Regnier's Abacus technique, which through the consensus of experts obtains results relevant to the ideal profile [10].

Because of the properties of the technique described and also that the accredited HEIs lack sufficiently reliable and valid instruments to evaluate the learning outcomes of the students and that there are differences in the evaluation of competences within departments and institutions, as well as between national and international institutions [11]. Therefore, the objective of this research was to propose a methodological guide that would allow to include the academic competencies to the syllabus that must be possessed by the student of systems engineering of the University of Cartagena, in addition to those obtained during its educational process.

\section{Materials And Methods}

A Non-experimental cross-sectional descriptive research was made due that the occurrences were observed naturally without intervention, data were obtained in a one moment and descriptive because of it was examined the influence of the levels of variables in the population [12].

\section{A. Data recollection instruments}

For recollection of information, interviews with the directives and professors of the Systems Engineering of the University of Cartagena were done, where it was asked for them about curriculum and the competences that compose it, in order to get references of the professional profile and establish required knowledge for marketing. Besides, documental review was used to define the required trends and technologies in the market and establish a model of the solicited professional.

\section{B. Data analysis}

Data processing and analysis were carried out employing the SoftProsp Software (Cartagena de Indias, Colombia) [13], which registered the qualificable ideas by professors. In the resultant matrix, the columns were represented as professors and rows the ideas, also, green colour meant the high favorability, dark red meant unfavorability and yellow meant impartiality, and meanwhile colours with soft tonality were intermediate levels between these.

\section{Proposed model}

The methodology for incorporating academic competencies in undergraduate programs is represented in the Fig. 1. This is based on the participation through reflexive processes, questionnaires, and consensuses in the stages, in order to integrate key knowledge to the profile of the student and to train qualified professionals.

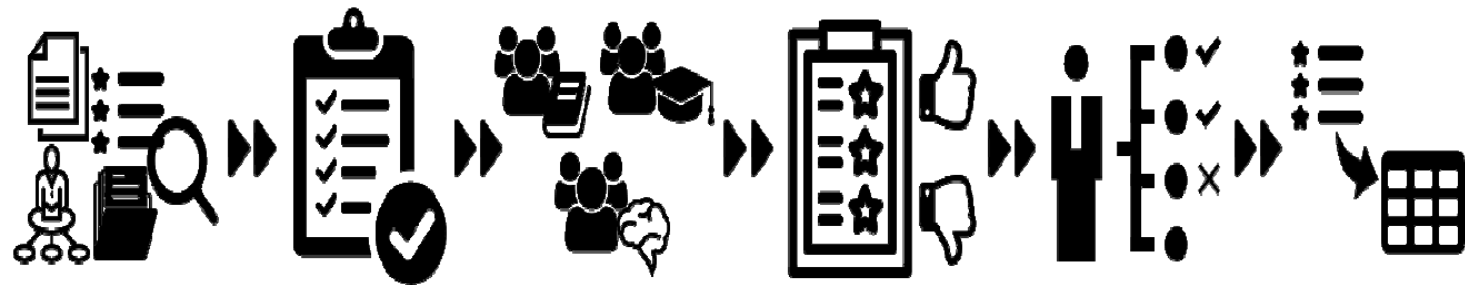

Fig. 1. Methodological guide to include academic competences to the university curriculum.

Following are the steps of the step-by-step guide for any academic program and what was done in the Systems Engineering program.

\section{Competences evaluation}

A review of the proposed competence and those existent in the curriculum were made, in order to check if this one was content and adapted to those existing. Thus, it was taken into account: curricular approach, social and market needs, changes in scientific knowledge and new trends. The importance to acquire the domain of SDN as competence lies in the fact that the interest of telecommunication companies in this topic has raised the requirements to improve the reliability of network systems and the ability to take control of their infrastructure, allowing customization, optimization, reducing general capital and operating costs [13]-[15].

\section{E. Definition of the subjects}

The temary that compose the proposed competences to verify its fit with the designated topics in the subjects of the curriculum was established and those that could be integrated to acquire these competencies were determined. 
In particular, this was obtained through consultations to teachers with knowledge in SDN, who also have a notion of the subjects and topics that are needed to manipulate this concept. The defined topics to reach the domain of SDN as competence were: Coding and signalling, guided and unguided media by sending data, detection and error correction methods, commutation, physical and logical addressing, routing (static and dynamic), protocols (Concepts), services (connected and unconnected), design patterns, object-oriented programming methodology and software modeling.

\section{F. Establishment of experts groups}

The expert group was conformed by 10 professors with knowledge in SDN, networking and software architecture of Systems Engineering program of the University of Cartagena.

\section{G. Level of competence relevance}

In this phase, the suitability of the proposed competencies for the professional of the program under study was determined through the application of Régnier's Abacus technique, which allowed the experts to vote on the topics that can be added and which should be reinforced with purpose of acquire this competence. The above produces a matrix that organizes the results, where the group of experts expresses and suggests about the valuations that others propose, in order to reach a consensus. These ideas are shown in Table 1.

Table 1. Evaluated ideas with Régnier’s Ábacus technique.

\begin{tabular}{cc}
\hline No. & Idea \\
\hline 1 & Do you know about SDN technology and its application? \\
2 & Do you consider that competence "domain of SDN technologies" is necessary for the training of a \\
3 & Systems Engineering professional? \\
4 & Does the academic program have the necessary resources to provide the proposed competence? \\
5 & Do you consider that the topic "Coding and Signalling” exists in the curriculum? \\
6 & Do you consider that the topic "Guided and unguided media by sending data" exists in the curriculum? \\
7 & Do you consider that the topic "Commutation" exists in the curriculum? \\
8 & Do you consider that the subject "Physical addressing" exists in the curriculum? \\
9 & Do you consider that the topic "Logical addressing” exists in the curriculum? \\
10 & Do you consider that the theme "Routing (static, dynamic)", exists in the curriculum? \\
11 & Do you consider that the topic "Protocols (concepts)" exists in the curriculum? \\
13 & Do you consider that the theme "Services (guided and non-guided)" exists in the curriculum? \\
14 & Do you consider that the theme "Design patterns, exists in the curriculum? \\
15 & Do you consider that the subject "OOP's methodology" exists in the curriculum? \\
16 & Do you consider that the theme Software Modelling exists in the curriculum? \\
\hline 17 & Do you consider that SDN competence can be added as part of an existing subject? \\
\hline
\end{tabular}

\section{H. Competences selection}

Results in applying the technique were analysed to establish what topics had major relevance to acquire the proposed competencies and determinate which were included in the curriculum.

I. Inclusion of competences

Defined competencies are included in the curriculum. Thus, subjects and topics that compose are reviewed for incorporating to the adequate semester.

\section{III.RESULTS AND DISCUSSIONS}

The results obtained are outlined in the Fig. 2. Regnier's Abacus technique allowed to easily evaluate the idea that are sustenance for incorporating competences to the curriculum. Comparing with other researches, an organizational framework was established to incorporating competences to the curriculum of a nursing program, which the professors were uncomfortable to evaluate a content that was out of their knowledge. Thus, it was necessary to make reunions to define the pertinent content that each student must acquire the proposed competences [16]. 
On the hand, in the Construction Management program of the Purdue University was implemented a Nominal Group technique to know the ideas of the members and debate between them, in order to get a consensus of competencies that will be added in the curriculum of the program [17]. The obtained data were analysed with a web application named Dedoose, which allowed the analysis of the content to find the ration of the obtained results. The above present a method to include academic competences, however, the obtained results are not debated to get results with greater support [18].

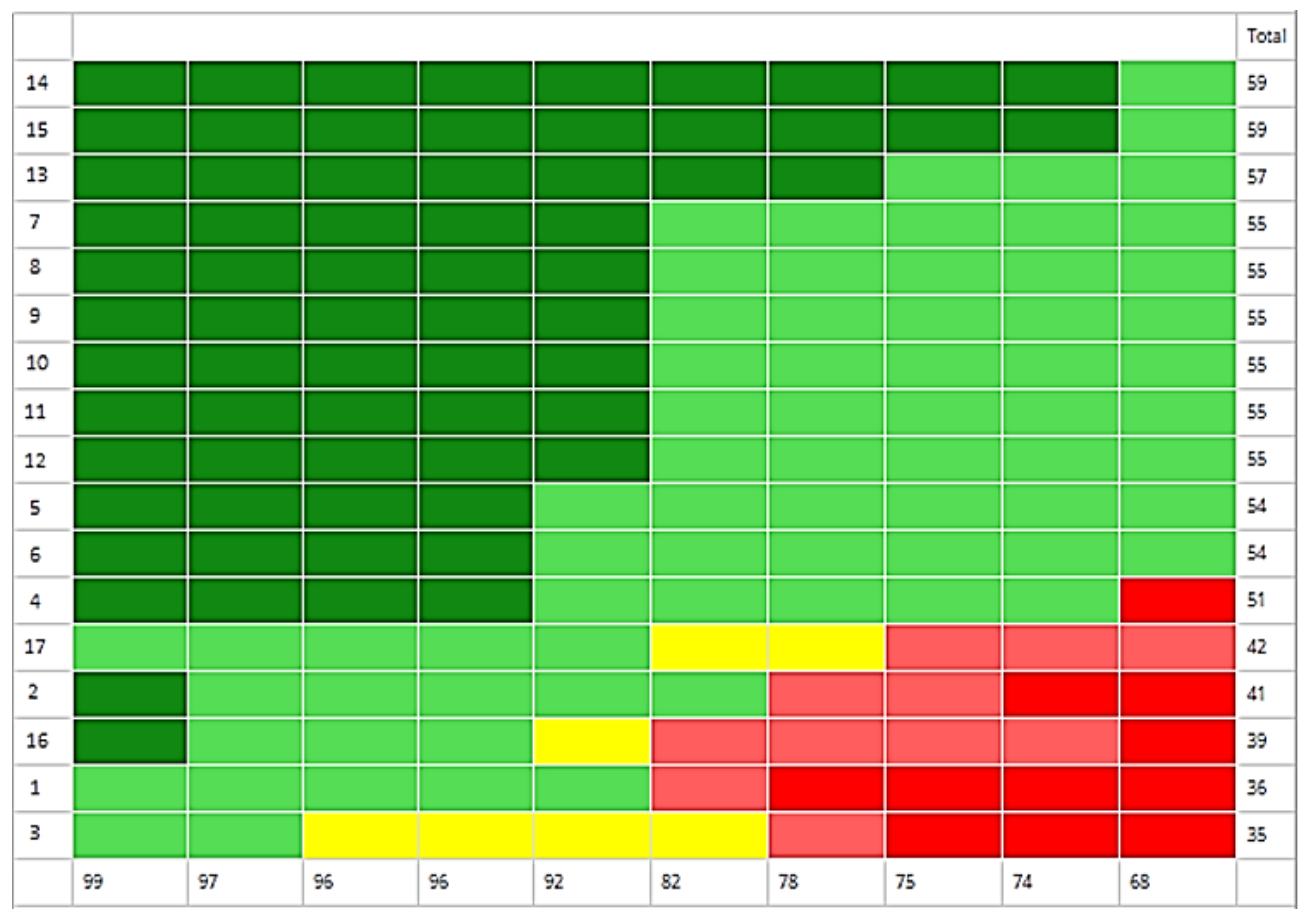

Fig. 2. Ideas evaluation matrix belonging to Régnier’s Abacus technique.

\section{A. Competences selection}

The professors considered that the necessary subjects to acquire the dominion of SDN as proposed competence, exist in the curriculum of the Systems Engineering program of the University of Cartagena, however, they did not have a completely favourable qualification reason why they have to improve based on technologies, market demand and current trends, so that the student can obtain the complete proposed competence. Regarding the idea whether it is necessary to add a new subject the program to reach the proposed competence, most experts rated it as favourable (50 \%), others with fairness (20\%) and unfavourable (30\%). Therefore, the incorporation of a subject in the curriculum that allows the student to acquire the necessary knowledge to be a competent professional should be considered. Likewise, this means the proposed competence is relevant to the constitution of a trained and up-to-date systems engineer.

On the other hand, the idea of adding the proposed competence to existing subjects obtained a divided opinion with a tendency towards unfavorability (50\%), which indicates that it is not feasible to add the academic content of the competence in these, for which a strategy must be proposed for achieve this objective. Regarding to the idea whether professors are aware of SDN's technology and its application, they presented very unfavourable votes (40\%) which implies a lack of updating of the curriculum provided by the academic program and should be adjusted to the market demand, technologies and current trends.

Finally, the evaluation of idea whether the academic program has the resources to offer the proposed competence, the results obtained showed a favourable (20\%), impartial (40\%) and unfavourable (40\%) opinions, which means a serious lack of human and technological resources on the part of the academic program and the need to improve this aspect.

\section{B. Inclusion of competences}

Table 2 shows the established topics to achieve the proposed competence and the subjects where they are contained. 
Table 2.Topics for the competence and subject

\begin{tabular}{cc}
\hline Topic & Subject \\
\hline Coding and Signaling & Networks I \\
Guided and unguided media of sending data & Networks I \\
Methods of detection and correction of errors & Networks I \\
Commutation & Networks I \\
Physical addressing & Networks I \\
Logical addressing & Networks I \\
Routing (static, dynamic) & Networks I, Networks II \\
Protocols (concepts) & Networks I, Networks II \\
Service (guided and non-guided) & Networks I \\
Design patterns & Software Engineering \\
OOP's Methodology & Object-oriented programming \\
Modeling Software & Software Engineering \\
\hline
\end{tabular}

The above, shows that the subjects required for competence are taught in the Systems Engineering program of the University of Cartagena, however, it does not have the approach towards learning SDN technologies, hence it is necessary to add another subject and update the topics described. The curriculum and professional profile must be adjusted to add the proposed competence and provide the graduate with the knowledge demanded by the market.

\section{IV.CONCLUSIONS}

The implementation of Regnier's Abacus process of adding competences to curriculum of the higher education institutions allows to support the training of professionals. Define competences according to the opinion of a group of professors provided a curriculum for technological trends and market demand. The domain of SDN technology as competence is essential for the systems engineer due to its usefulness in the control and security of a network infrastructure and a web application. To standardize the process of integrating competences in the curriculum using Régnier's Abacus, it is pertinent to improve the quality of professionals. The guide for the introduction of defined competencies helps in analyzing the state of the curriculum for finding shortcomings.

\section{REREFENCES}

[1] A. Tekian, B. D. Hodges, T. E. Roberts, L. Schuwirth, and J. Norcini, “Assessing competencies using milestones along the way,” Med. Teach., vol. 37, no. 4, pp. 399-402, 2015.

[2] O. Jerez, L. Valenzuela, V. Pizarro, B. Hasbun, G. Valenzuela, and C. Orsini, "Evaluation criteria for competency-based syllabi: A Chilean case study applying mixed methods,” Teach. Teach. Theory Pract., vol. 22, no. 4, pp. 519-534, 2016.

[3] Á. D. Barriga, "El enfoque de competencias en la educación.¿UNA ALTERNATIVA O UN DISFRAZ DE CAMBIO?,” Rev. UNIMAR, vol. 26, no. 3, pp. 67-86, 2014.

[4] M.-C. Pop and C.-A. Mazilescu, "Competence-Based Curricular Design for Foreign Language Teaching in the Romanian Technical Universities,” Procedia - Soc. Behav. Sci., vol. 46, pp. 4200-4204, 2012.

[5] I. Harpan and A. Draghici, "Competencies in Use and Exploitation: A Proposed Research Methodology,” Procedia-Social Behav. Sci., vol. 109, pp. 193-197, 2014

[6] S. ur Rehman, "Developing new competencies among LIS professionals: Challenges for educators," Pakistan J. Libr. Inf. Sci., p. 67, 2008.

[7] J. D. Correa, "Examinando el futuro: Metodología propuesta para el estudio prospectivo y estratégico de la Universidad de Cundinamarca (2010-2019).," Esquemas Pedagog., vol. 9, no. 1, pp. 7-10, 2011.

[8] M. Godet, P. Durance, and A. Gerber, "Strategic Foresight La Prospective," Paris, Lab. d'Investigation en Prospect. Strat. Organ., 2006.

[9] J. H. Ospina Baena and M. M. Correa Peña, "El hurto de automotores bajo el enfoque prospectivo: una caracterización actual y futura de la actividad criminal en Colombia,” Rev. Crim., pp. 9-25, 2015.

[10] R. Martelo, V. N, and I. Jiménez-Pitre, "Guía metodológica para definir el perfil profesional de programas académicos mediante la herramienta ábaco de Régnier,” Form. Univ., vol. 10, no. 1, pp. 15-24, 2017.

[11] O. Zlatkin-Troitschanskaia, H. Anand, C. Kuhn, M. Toepper, and C. Lautenbach, "RESEARCH \& PRACTICE IN ASSESSMENT," Res. Pract. Assess., vol. 11, no. 1, pp. 46-54, 2016.

[12] C. Hernández-Sampieri, R. Fernández Collado and P. Baptista-Lucio, Metodología de la investigación, 4 edition. 2006.

[13] A. Cabarcas, R. Martelo, and L. Tovar, "Software para mejorar la aplicación de técnicas cuantitativas en estudios prospectivos Resumen Résumée,” vol. 29, pp. 64-74, 2013.

[14] C. Ferreira et al., “Towards a Carrier Grade SDN Controller: Integrating OpenFlow with Telecom Services,” 2014, pp. 70-75.

[15] S. Naveed, D. Raumer, F. Wohlfart, and G. Carle, “Towards carrier grade SDNs,” Comput. Networks, vol. 92, pp. 2018-226, 2015.

[16] M. T. Hickey, M. Forbes, and S. Greenfield, "Integrating the Institute of Medicine Competencies in a Baccalaureate Curricular Revision: Process and Strategies,” J. Prof. Nurs., vol. 26, no. 4, pp. 214-222, Jul. 2010.

[17] B. L. Benhart and M. Shaurette, "Establishing New Graduate Competencies: Purdue University's Construction Management Curriculum Restructuring,” Int. J. Constr. Educ. Res., vol. 10, no. 1, pp. 19-38, Jan. 2014.

[18] K. Koh and J. Abbas, “Competencies for Information Professionals in Learning Labs and Makerspaces,” J. Educ. Libr. Inf. Sci. Online, vol. 56, no. 2, pp. 114-129, 2015. 


\section{AUTHOR PROFILE}

Raúl J. Martelo works as full-time professor at the University of Cartagena (Colombia). Mr. Martelo completed his magister from Industrial University of Santander (Colombia). Mr. Martelo completed his undergraduate in Systems Engineering at the Industrial University of Santander.

Diofanor Acevedo Correa works as full-time professor in the University of Cartagena (Colombia). Dr. Acevedo completed his doctorate from University of Valle (Cali-Colombia). Mr. Acevedo completed his undergraduate in Food Engineering and Pharmaceutical Chemistry at the University of Cartagena.

Piedad M. Martelo works as part-time professor at the University of Cartagena (Colombia). Mrs. Martelo completed her specialization studies from Universidad of Cartagena. Mrs. Martelo completed his undergraduate in Dentistry at the University of Cartagena. 